\title{
Gold in Bimetallic Catalysts
}

\author{
Johannes Schwank \\ Department of Chemical Engineering, The University of Michigan, Ann Arbor, U.S.A.

\begin{abstract}
In spite of its low intrinsic catalytic activity, gold can influence the activity and selectivity of group VIII metals, such as palladium, platinum and ruthenium. Gold-containing bimetallic catalysts have found important industrial applications and represent an active research area for elucidating the correlation between surface structure and catalytic activity.
\end{abstract}

In a recent article in this journal the applications of elemental gold in heterogeneous catalysis were reviewed with emphasis on monometallic gold catalysts (1). In the present review, the application of gold as a component in bimetallic catalysts is discussed. Special attention is paid to examples of bimetallic catalysts where the addition of gold appears to increase the catalytic activity or significantly influence the selectivity of the catalyst.

Early work on bimetallic catalysts aimed at correlating the catalytic behaviour and the electronic structure with alloy composition. Alloys of palladium, a group VIII metal having in excited states a partially unoccupied $d$-band, and gold with a completely filled $d$-band were studied (2-6) and attempts were made to interpret the results on the basis of the rigid band theory.

However, it turned out that the observed catalytic activities could not unambiguously be correlated with increasing occupancy of $d$ bands in the alloys as a function of gold content. More recently, strong arguments have been put forward in favour of localized effects in catalysis where the two metal components in an alloy retain more or less their individual electronic structures (7).

Adding gold to an active group VIII metal makes it possible to study not only electronic but also structural effects in catalysis. In reactions which require certain ensembles or clusters of active metal atoms, the presence of gold atoms with intrinsically low catalytic activity can dilute or distupt such ensembles of active surface atoms and thus cause precipitous drops in activity as a function of gold content. Under certain conditions, the gold induced changes in available active groupings of group VIII metal atoms can lead to different selectivities. Of course, it is not always possible to clearly disentangle structural from electronic or 'ligand' effects (8).

The preparation of bimetallic catalysts is not restricted to metal components which are capable of forming solid solutions over the full composition range, but can also include elements which have limited miscibility such as platinum and gold, or even complete immiscibility. An example of the latter type is the ruthenium-gold system. Bimetallic systems with limited bulk miscibility offer the intriguing opportunity of investigating whether the bulk miscibility limitations start to break down at very high metal dispersions. The term 'bimetallic clusters' (9) or 'bimetallic aggregates' has been coined to describe the as of yet not fully understood structures of the metal particles in these bimetallic catalysts.

In the following, the effects of gold on the catalytic behaviour of palladium, platinum and ruthenium will be reviewed. This should make it possible to address fundamental questions of bimetallic cluster and alloy formation, for palladium forms solid solutions with gold over the entire composition range, while the platinum-gold system displays limited bulk miscibility, and the two metals ruthenium and gold are completely immiscible in the bulk.

\section{Palladium-Gold}

The two metals gold and palladium crystallize in a face-centred cubic structure with lattice parameters of $0.4078 \mathrm{~nm}$ and $0.3890 \mathrm{~nm}$, respectively, and form a continuous series of solid solutions. The standard free energy of single-phase alloy formation is negative over a wide range of temperature (10). In view of the great similarity between the atomic radii and the heats of vaporization of gold and palladium, the surface compositions of their alloys should not deviate markedly from the bulk compositions, at least under vacuum conditions (11). Prolonged heating, in particular in presence of oxygen, can lead to enrichment of the surface with gold (12-15). Electron Spin Resonance (ESR) data obtained on aluminasupported palladium-gold samples indicated that the gold concentration at the surface of the alloys might be larger than in the bulk even after hydrogen treatment at high temperatures (16). Direct evidence for alloy formation in small, silica-supported goldpalladium particles of 2 to $4.5 \mathrm{~nm}$ diameter was obtained in a Mössbauer study; the results of selective gas chemisorption along with data from wide-angle $\mathrm{X}$-ray line broadening indicated that the surface composition of these particles was similar to their overall composition (17). The existence of $\mathrm{Pd}_{m} \mathrm{Au}_{\mathrm{n}}$ ensembles was also confirmed by diffraction patterns obtained on goldpalladium/silica catalysts used for hydrogenation of unsaturated compounds (18).

In many instances, addition of gold to palladium results in a decrease of catalytic activity relative to that of palladium itself. There are, however, cases where this loss in activity is at least partially counterbalanced by improvements in selectivity. For example, the activity of gold-palladium alloys in the oxidation of ethylene was much lower than that of palladium alone. However, the selectivity for production of partial oxidation products such as acetic acid, acetic anhydride and acetaldehyde went through a maximum when the alloy composition reached about 80 per cent gold and 20 per cent palladium $(19,20)$. As a possible explanation, the authors suggested that the complete oxidation of ethylene would require an adsorption of ethylene on adjacent palladium atoms, while the partial oxidation would occur on single palladium sites. Adding gold would decrease the availability of dual palladium adsorption 
sites, and thus favour the partial oxidation (19). High selectivity for acetic acid production via the catalytic vapour phase oxidation of ethylene can also be obtained on supported gold-palladium catalysts containing $\mathrm{H}_{3} \mathrm{PO}_{4}(21)$ or $\mathrm{SO}_{2}(22)$. A catalyst containing gold, palladium and platinum in the form of precipitated metal hydroxides was found to be suitable for the oxidation of propene to malonic acid (23). Acetaldehyde can be oxidized to aceric acid on silica-supported gold-palladium catalysts (24). In a recent patent, alloy wires containing more than 85 weight per cent palladium and more than 3 weight per each of rhodium and gold were found to have excellent performance in the catalytic oxidation of ammonia to nitric acid (25).

While in the above examples catalytic activity was to a certain extent sacrificed at the expense of higher product selectivity, a significant enhancement of the rate of the water formation from interaction of hydrogen and oxygen (26) and for oxidative dehydrogenation (27) was reported for silica-supported goldpalladium catalysts. Figure 1 (taken from (26)) shows how the turnover frequency for the $\mathrm{H}_{2}-\mathrm{O}_{2}$ reaction (expressed in terms of molecules of $\mathrm{H}_{2}$ reacted per surface palladium atom per second) goes through a maximum at intermediate gold content. Structural effects such as dilution of active palladium ensembles by inactive gold were ruled out as providing an explanation for the maximum in view of the structure-insensitivity of the reaction between $\mathrm{H}_{2}$ and $\mathrm{O}_{2}$ over pure palladium. The fifty-fold increase in activity at intermediate gold content was explained instead on the basis of a ligand effect causing a decrease in the apparent activation energy of the reaction; it was suggested that the binding energy of oxygen to palladium decreases when palladium atoms are surrounded by gold (26). The decrease in oxygen binding energy due to addition of gold to palladium was confirmed in a comparative single crystal study of water synthesis on palladium (111) and palladium-gold (111) surfaces (28). It was also found that the addition of gold to palladium caused a drastic reduction in oxygen surface coverage.

In contrast to the findings on silica-supported gold-palladium (26), the results of a single crystal study indicated that the pure palladium (111) surface was more active than the corresponding palladium-gold surface (28). Under the conditions of the singlecrystal experiment, the reaction probability was found to be 5 orders of magnitude larger than in the atmospheric pressure study (26). The seemingly contradictory results obtained at low-pressure versus atmospheric pressure can be reconciled by the fact that one prerequisite for the reaction is the ability of hydrogen to adsorb on the surface in the form of a precursor state with high mobility. At low pressure, the oxygen surface coverage of palladium is less than 12 per cent, leaving a large fraction of palladium surface sites available to accommodate hydrogen. At atmospheric pressure under excess oxygen, the palladium sites are almost completely covered by oxygen, with only a few sites left for hydrogen adsorption. Addition of gold leads to a decrease in oxygen coverage, even under atmospheric pressure conditions, and thus makes additional

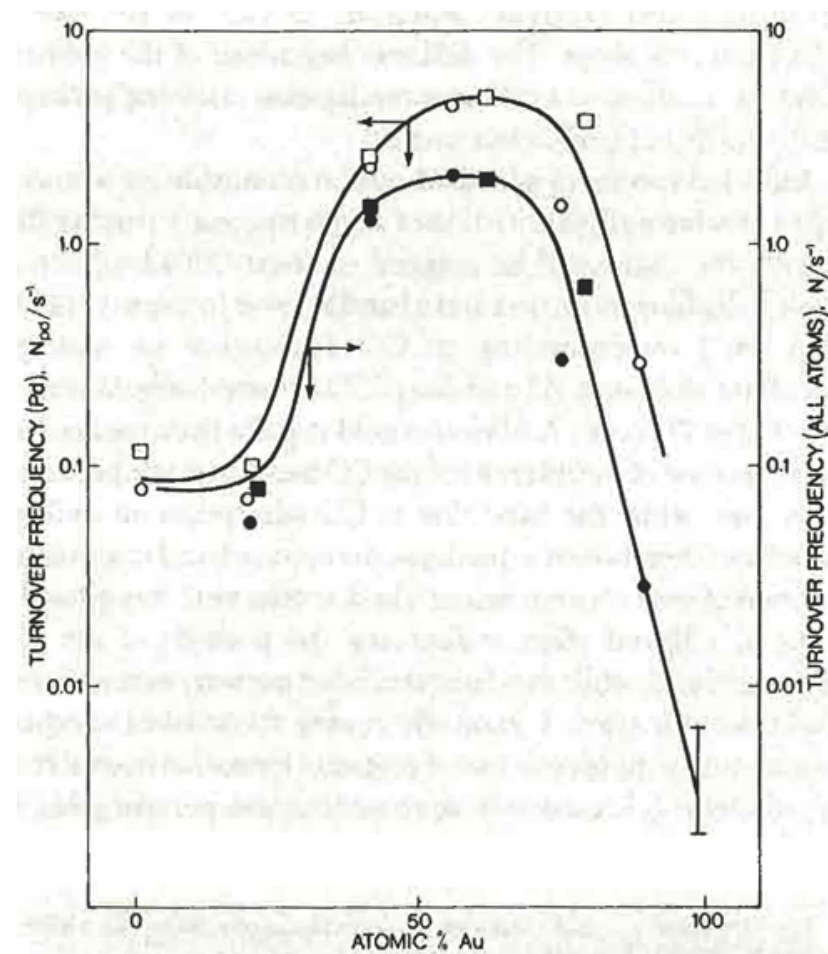

Fig. 1 Activity for water formation from $\mathrm{H}_{2}$ and $\mathrm{O}_{2}$ at $263 \mathrm{~K}$ over palladium-gold catalysts as a function of alloy composition. The turnover frequency $\mathrm{N}_{\mathrm{N}}$ is defined as the number of molecules of $\mathrm{H}_{2}$ reacted per surface palladium atom per second. The tumover frequency $\mathrm{N}$ is determined with respect to all surface atoms, whether they are gold or palladium. After (26)

palladium sites available for hydrogen adsorption, resulting in increased activity in the $\mathrm{H}_{2}-\mathrm{O}_{2}$ reaction. In this context it is interesting to note that some of the oxygen adsorbed on palladium (111) seemed to be adsorbed in form of a second, nonreactive state which was not observed on palladium-gold (111) surfaces (28).

The adsorption and reaction of $\mathrm{CO}$ and $\mathrm{O}_{2}$ on palladium-gold alloy wires studied by Eley and co-workers $(4,8)$. In the reaction between $\mathrm{CO}$ and $\mathrm{O}_{2}$ leading to the formation of $\mathrm{CO}_{2}$, apparent activation energies of about $9 \mathrm{kJoule} / \mathrm{mole}$ were found for gold-rich alloys with an abrupt increase to about 120 to $170 \mathrm{kJoule} / \mathrm{mole}$ for gold-palladium alloys containing less than 60 atomic per cent gold. The reaction rate was lowest on gold-rich alloys in spite of the extremely low activation energy. The observed kinetics indicated that oxygen-adsorbing gold sites were saturated under the reaction conditions and that probably only a small number of special sites such as gold atoms at dislocations or perhaps even impurity atoms were involved. It was suggested that the adsorption and reactivity of the gold-palladium alloy wires associated with particular $\mathrm{Pd}_{n} \mathrm{Au}_{\mathrm{m}}$ surface atom ensembles where neighbouring atoms exert electronic or ligand effects. The existence of ensembles of eight to ten palladium atoms appeared to be the determining factor for $\mathrm{CO}$ 
adsorption and catalytic oxidation to $\mathrm{CO}_{2}$ in the case of palladium-rich alloys. The different behaviour of the gold-rich alloys was ascribed to a different mechanism involving perhaps a small number of gold defect sites (8).

Infra-red spectra of adsorbed carbon monoxide on a series of gold-palladium alloys (29) showed a high frequency band at 2070 to $2095 \mathrm{~cm}^{-3}$ that could be assigned to linear $\mathrm{CO}$ adsorption on single palladium atom sites and a band at lower frequency (1870 to $1925 \mathrm{~cm}^{-1}$ ) corresponding to $\mathrm{CO}$ adsorption on multiple palladium atom sites. A band due to $\mathrm{CO}$ adsorbed on gold sites was detected at $2115 \mathrm{~cm}^{-1}$. Addition of gold to palladium resulted in a linear decrease of the intensity of the $\mathrm{CO}$ band on single palladium atom sites, while the band due to $\mathrm{CO}$ adsorption on multiple palladium sites showed a quadratic decrease in band intensity as a function of gold concentration. These results were interpreted in terms of a ligand effect influencing the position of the high frequency band, while the changes in band intensity were indicative of an ensemble effect. Ligand effects were also invoked to explain a maximum in the specific rate of propanol formation from acetone on palladium-gold catalysts with about 50 atomic per cent gold (30).

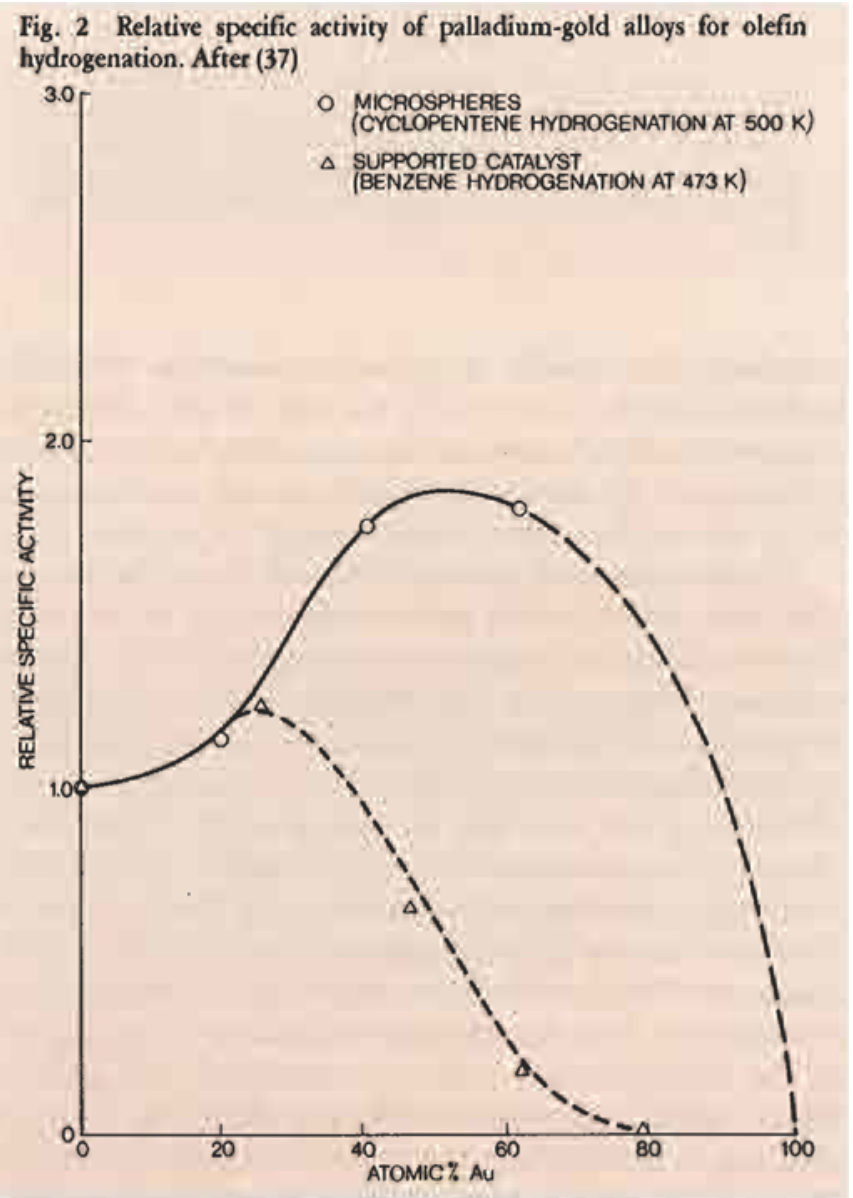

Numerous studies have been devoted to the activity of palladium-gold catalysts in the hydrogenation of unsaturated hydrocarbons and in the dehydrogenation of saturated hydrocarbons. While the addition of copper or silver to palladium resulted in a drop in benzene hydrogenation activity, gold reportedly did not cause any loss in activity $(31,32)$ regardless of the method of deposition of the two metals on the surface of the silica support. In fact, in one instance where the catalyst contained 0.2 per cent palladium and gold was deposited jointly with palladium, the benzene hydrogenation activity increased with increasing gold content and went through a maximum at intermediate gold levels (31). Similar activity trends were observed in the dehydrogenation of cyclohexane on the same catalysts (33). On a palladium-nickel tube whose external surface was covered by gold, cyclohexane was dehydrogenated into benzene; the hydrogen formed in the course of the dehydrogenation reaction did not desorb into the gas phase but diffused through the palladium membrane and hydrogenated cyclohexene to cyclohexane (34). These findings agree with earlier experiments in which atomic hydrogen was supplied via diffusion through a palladium-silver membrane to a gold surface upon which cyclohexene was hydrogenated to cyclohexane $(35,36)$.

On palladium-gold alloys in the form of microspheres, a pronounced increase in specific activity for the hydrogenation of cyclopentene was found with a maximum at a gold content of about 50 atomic per cent (37). However, when palladium and gold were dispersed on alumina, a different behaviour was found (see Figure 2 taken from (37)). In the latter case, the surface of the metal particles might not have been in equilibrium with the bulk. O'Cinneide and Clarke, however, found that gold-palladium films lost their activity for deuteration of benzene and for hydrogenation of $p$-xylene when the gold content exceeded about 50 per cent (38) while the activity for deuterium exchange of hydrogen atoms on the benzene ring persisted $(38,39)$ although with significantly lower rates at high gold contents.

Already in 1957, a patent was granted to Dow Chemical Co. for the selective hydrogenation of acetylene to ethylene on catalysts containing palladium and a group Ib metal (40). These catalysts proved to be useful for removing acetylene from mixtures containing acetylene and ethylene. On unsupported goldpalladium powders, Visser etal. (41) observed that the activity for hydrogenation of acetylene and cyclopropane passed through a maximum as a function of alloy composition. Rushford and Whan (42), on the other hand, found a dramatic decrease in activity for hydrogenation of dimethylacetylene as a function of gold content. Typically, gold additions induced activity losses in hydrogenolysis reactions, such as the hydrogenolysis of hexane (41). In the latter reaction, however, the selectivity for methylcyclopentane formation seemed to increase as a function of gold content (41). A decrease in activity for isomerization and hydrocracking of hexanes was also seen on alumina-supported gold-palladium catalysts; there was, however, no major change in selectivity observed (43). In the gas- 
phase hydrogenation of butadiene on supported gold-palladium catalysts, gold seemed to have only a small effect on the mechanism of the hydrogenation (44). Interestingly, both the selectivity for 1-butene formation and the apparent activation energies showed a sharp maximum at gold contents of 65 to 70 atomic per cent. Alloys containing more than 70 per cent gold seemed to behave like alloys in the 0 to 60 per cent gold range which fell on the other side of the maximum. At low gold concentrations, the palladium-gold alloy exhibits paramagnetic behaviour due to the presence of unpaired electrons. According to the then widely accepted rigidband theory (6), gold atoms would contribute electrons to the partially unoccupied $d$-band of the alloy until at gold levels of 50 to 60 atomic per cent the $d$-band of the alloy would be completely filled. Consequently, all the electrons in the $d$-band would be paired resulting in a transition from paramagnetic to diamagnetic behaviour. The similar catalytic behaviour of alloys on both sides of the maximum in spite of the loss of paramagnetism in the goldrich alloys with more than 70 per cent gold indicated that the simple electronic theory of catalysis based on the rigid-band model was not adequate to describe the observations.

Other examples of the influence of gold on selectivity relate to gold-palladium/alumina catalysts developed by Sinfelt and coworkers at Exxon Research and Engineering Company $(45,46)$. When heptane and hydrogen were passed at $454^{\circ} \mathrm{C}$ and 14.6 atmospheres pressure over catalysts containing 0.6 weight percent palladium and 0.1 to 1.2 weight per cent gold, the selectivity to C1-C6alkanes and toluene decreased as a function of gold content, while the selectivity to methylhexanes and dimethylpentanes increased steadily from 50 per cent on pure palladium to 80 per cent on the gold-rich catalyst. The conversion of $n$-heptane did not show any clear trend as a function of gold content. Monometallic gold had much lower activity than the bimetallic catalysts and gave high selectivity ( $>75$ per cent) to C1-C6 hydrocarbons (45). Under similar reaction conditions, addition of gold to palladium resulted in increased selectivity for the conversion of methylcyclopentane to benzene (46). The elucidation of the role of gold in these catalysts is complicated by the fact that the acidic sites of the alumina support contribute to the activity via bifunctional catalysis. Nevertheless, there seems to be a general trend for gold drastically to decrease the hydrogenolysis activity of group VIII metals without affecting the activity for dehydrogenation and isomerization to a significant extent. This behaviour can be exploited in catalytic reforming (47) and hydrocracking processes (48). Gold seems also to be beneficial in isomerization reactions of pinene (49).

The decomposition of formic acid on gold-palladium alloy films was reviewed by Moss and Whalley (50). An abrupt change of the apparent activation energy with alloy composition was observed (3, 51), reminiscent of similar observations in parahydrogen conversion (2) (see Figure 3). In the parahydrogen conversion, the abrupt increase in activation energy occurred at 40 atomic per cent palladium which was correlated with a complete filling of the

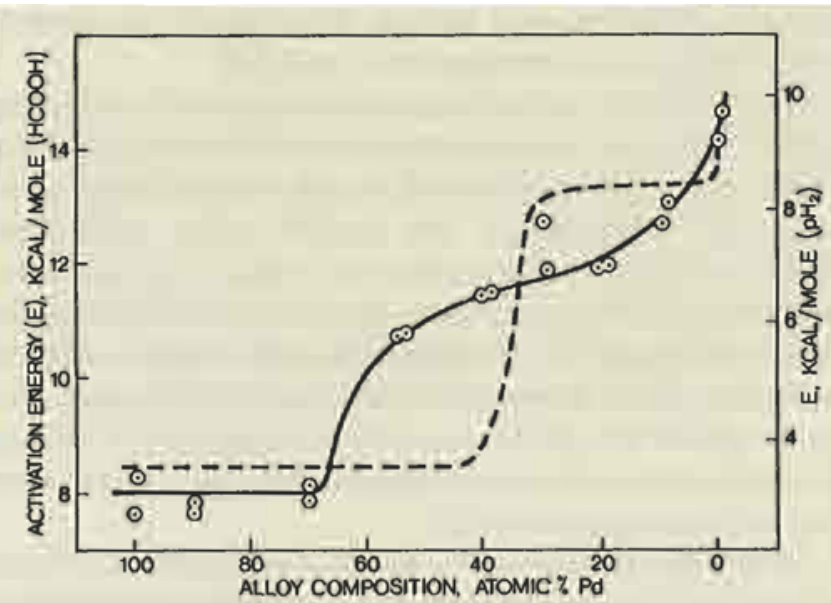

Fig, 3 Activation energy for the decomposition of formic acid (solid lines) and for the parahydrogen conversion (dotted lines) as a function of alloy composition. After (3)

$d$-band in the alloy (2). In the formic acid decomposition, however, the increase in apparent activation energy took place at around 60 atomic per cent palladium $(3,51)$. In an attempt to reconcile these results with the then prevailing rigid-band theory, Eley and Luetic attributed this discrepancy to different site requitements for the activated complex in the two reactions (3). Later on, in a study of hydrogen peroxide decomposition on gold-palladium alloys, it was realized that the correlation of activity with holes in the $d$-band of the alloys was not fully justified and that large changes in activity could result from differences in surface pretreatment and oxygen surface coverage (52). In gold-palladium alloys supported on alkaline earth carbonates, gold seemed to increase the catalytic efficiency in the hydrogen peroxide decomposition, in contrast to silver which acted as a catalyst poison $(53,54)$.

The patent literature contains numerous claims concerning the use of bimetallic palladium-gold catalysts, usually supported on silica, for the industrial scale production of vinyl acetate from ethylene and acetic acid in presence of oxygen(55-74). In some cases, alumina (65), tin dioxide (62), or a zinc spinel (66) is used as catalyst support instead of silica. Typical catalysts contain about 0.7 to 1.6 per cent palladium and 0.2 to 0.5 per cent gold along with several weight per cent of alkali metal carboxylates. In a few instances, chlorine (62) or uranium (66) are added. The reaction is carried out in the gas phase at temperatures of 140 to $190^{\circ} \mathrm{C}$ and at pressures of 6 to 11 atmospheres. Typical feedstreamscontain 60 to 70 ethylene / 20 to 30 acetic acid / 6 to 10 oxygen per cent and the balance in form of inert gases. Vinyl acetate is obtained in high yields with carbon dioxide as a by-product. Addition of 10 per cent methane to the feed stream tends to increase the lower explosion limit and thus allows a higher oxygen concentration resulting in an increased vinyl acetate space-time yield (68). While the role of gold is not entirely clear, large increases in catalytic activity are observed in 
bimetallic palladium-gold catalysts as compared with similarly prepared palladium catalysts without gold (62).

In a comparative study of the gas phase synthesis of vinyl acetate at 190 to $120^{\circ} \mathrm{C}$ and 6 atmospheres on various bimetallic palladium catalysts, it was found that the yield, the selectivity and the ethylene conversion decreased in the catalyst order palladiumgold $>$ palladium- $R E>$ palladium-cobalt $>$ palladiumrhodium $>$ palladium-ruthenium, where the symbol $R E$ stands for rare earth elements (75). The palladium-gold catalysts used for the production of vinyl acetate which show signs of deactivation after a prolonged time on stream can easily be regenerated by treating them with aqueous solutions of sodium acetate $(76,77)$ or by a more involved multistep process (78).

Other olefins and carboxylic acidscan be substituted for ethylene and acetic acid, respectively, to prepare a variety of unsaturated esters of carboxylic acids $(60,64,66,84)$. Gold-palladium/potassium acetate catalysts supported on silica can also be used to prepare phenyl acetate from benzene and acetic acid in a $\mathrm{N}_{2} / \mathrm{O}_{2}$ gas stream (79). Similarly, benzyl acetate can be obtained by passing a gas mixture containing toluene and acetic acid in presence of oxygen and water over a catalyst containing palladium and gold (80). Acyloxyalkenes react with acetic acid and oxygen in presence of fluidized catalysts containing 1 percent palladium, 0.4 percent gold and 3 per cent potassium to give diacyloxyalkenes (81). These products have fungicidal, nema tocidal and bactericidal properties. When lower alkyl acetals are brought in contact with a catalyst containing 1 per cent palladium, 0.4 per cent gold and 6 per cent potassium acetate, they undergo a cleavage into unsaturated ethers at a temperature of $300^{\circ} \mathrm{C}(82)$. Bimetallic gold-palladium catalysts can also be used to eliminate formic acid impurities from acetic acid (83), and for the formation of propionaldehyde from allyl alcohol which in turn is obtained via hydrolysis of allyl acetate (85).

Palladium-gold catalysts have also found applications in the production of butyrolactones (86), ethylene glycol (87), and deoxy-5-hydroxytetracycline (88), and have been shown to have activity for reduction of nitrophenol $(89,90)$ and for carbonylation of chloroalkenes (91).

\section{Platinum-Gold}

The platinum-gold system forms a continuous series of solid solutions only at very high temperatures. Below $1150^{\circ} \mathrm{C}$, the mutual solubility of the two elements decreases resulting in a miscibility gap. Within this miscibility gap, a gold-rich phase coexists with a platinum-rich phase $(92,93)$. The structure and surface composition of bimetallic gold-platinum catalysts, and whether or not equilibrium conditions and alloy formation are achieved, depends uponthe details of sample preparation and pretreatment (94-113). Depending on the nature of the catalyst support used, repeated oxidation/reduction cycles can lead to massive differences in selectivity which might be due to the segregation of platinum (114). This phenomenon which was observed on alumina supports does not seem to exist in the case of silica-supported platinum-gold catalysts. If, on the other hand, the two metals do not segregate, then gold on the platinum surface causes ensemble effects. Such effects are manifested, for example, in changes in carbon monoxide adsorption $(115,140)$ or in the product distributions in cyclopentane deuteration (116), n-hexane conversion (140) and cyclohexane dehydrogenation (117, 141).

The isomerization, dehydrocyclization and hydrogenolysis reactions of $\mathrm{n}$-pentane and $\mathrm{n}$-hexane were investigated on gold-rich alloys supported on silica (118). While pure platinum catalysts favoured mainly isomerization reactions via a bond-shift mechanism, alloys with about 10 per cent platinum showed mainly dehydrocylization and some isomerization activity via a cyclic intermediate, a behaviour reminiscent of highly dispersed platinum. Isomerization reactions via a one-site carbonium ion-like mechanism seemed to become predominant in extremely diluted alloys containing less than 4 per cent platinum. Clarke, Kane and Baird, on the other hand, found no detectable cyclization activity in the n-pentane/hydrogen reaction on a silica-supported goldplatinum catalyst containing 10 per cent platinum (119). This catalyst, however, seemed to have only a very small amount of platinum on the surface because it had al most negligible hydrogen chemisorption capability. Reduction of the platinum-gold catalysts in hyd rogen gave generally higher activity in $n$-hexane conversion than reduction in hydrazine (94). The hydrazine reduction seemed to lead to the formation of a platinum-rich phase enveloped by a gold-rich phase. Equilibrium surface enrichment by gold requires a suitable thermal treatment; once gold is on the surface it tends to behave more or less as an inert diluent, although some spillover of atomic hydrogen from platinum sites onto gold sites can occur (106).

Skeletal reactions of hydrocarbonson platinum can be strongly influenced by addition of gold (120). The isomerization of neopentane goes through a maximum at intermediate gold content, a result that can be explained on the basis of ensemble

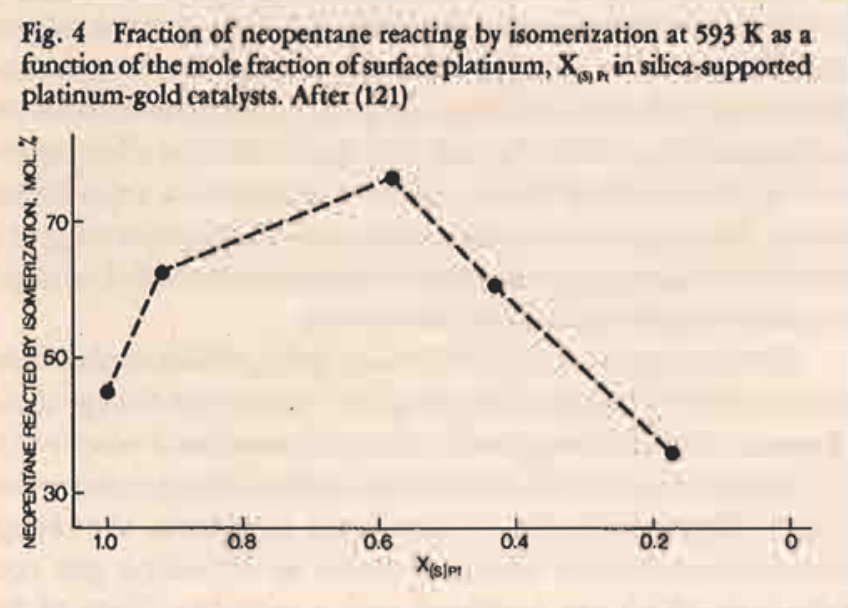


effects and availability of adsorbed hydrogen(121) (Figure 4). In the case of isomerization of $n$-butane on alloy films, significant amounts of $\mathrm{n}$-pentane were found at temperatures above $300^{\circ} \mathrm{C}$ in addition to the expected isomerization and cracking products (122). The authors attributed this unusual catalytic behaviour to an apparent disproportionation of $\mathrm{n}$-butane.

In experiments on platinum-gold foils, gold addition caused selectivity enhancements for isomerization reactions of alkanes due to more pronounced suppression of hydrogenolysis and dehydrocyclization reactions (123). After depositing one monolayer of gold on top of a $\mathrm{Pt}(100)$ single crystal surface, a massive increase was observed in the rate of cyclohexene dehydrogenation to benzene (124) (Figure 5). Interestingly, a similar effect was observed when one or two monolayers of platinum were deposited on a $\mathrm{Au}(100)$ surface which, by itself, was totally inactive under the experimental conditions (124). According to the authors, gold could block platinum surface sites required for breaking of carbon-carbon bonds, thus preventing surface deactivation by carbon deposition. When gold is deposited on top of a platinum (100) surface, it experiences a slight contraction in atomic distances bringing the gold atoms into precise registry with the platinum atoms underneath. It was proposed that cyclohexene could bond to the platinum atoms in the second layer through the relatively large hollows in the square lattice of the gold surface monolayer.

When gold was deposited on platinum (111) single crystal surfaces which were subsequently annealed to form a surface goldplatinum alloy, large increases in the isomerization rate of $n$-hexane were found while hydrogenolysis and aromatization rates decreased with gold concentration (140). The enhancement of the hexane isomerization rate was believed to be due to changes in bonding of the hydrocarbon caused by either charge redistribution or geometric effects of the platinum clusters.

The activity of platinum-gold catalysts in the hydrogenation of benzene showed a maximum at about 5 atomic per cent gold; larger gold contents caused a decrease in activity and at 75 atomic per cent gold no detectable activity remained (125). A similar maximum in activity was found in the hydrogenation of ethylene on monodisperse platinum-gold sols (98). A catalyst containing 62 per cent gold showed a 2.5 fold increase in activity over one of pure platinum. According to the authors, this maximum might be associated with a cluster of two gold atoms and one platinum atom. The rates of catalytic dehydrogenation of propane to propene over platinum-gold powders containing up to 14 atomic per cent platinum declined almost linearly with decreasing bulk platinum content (126). The authors suspected that only one platinum atom is involved in the rate determining step and that there is no fundamental difference in the reaction mechanism on the alloys versus pure platinum. The surfaces of the diluted platinum-gold alloys seemed to be depleted of hydrogen compared with a pure platinum surface, as evidenced by differences in the reaction order with respect to hydrogen.

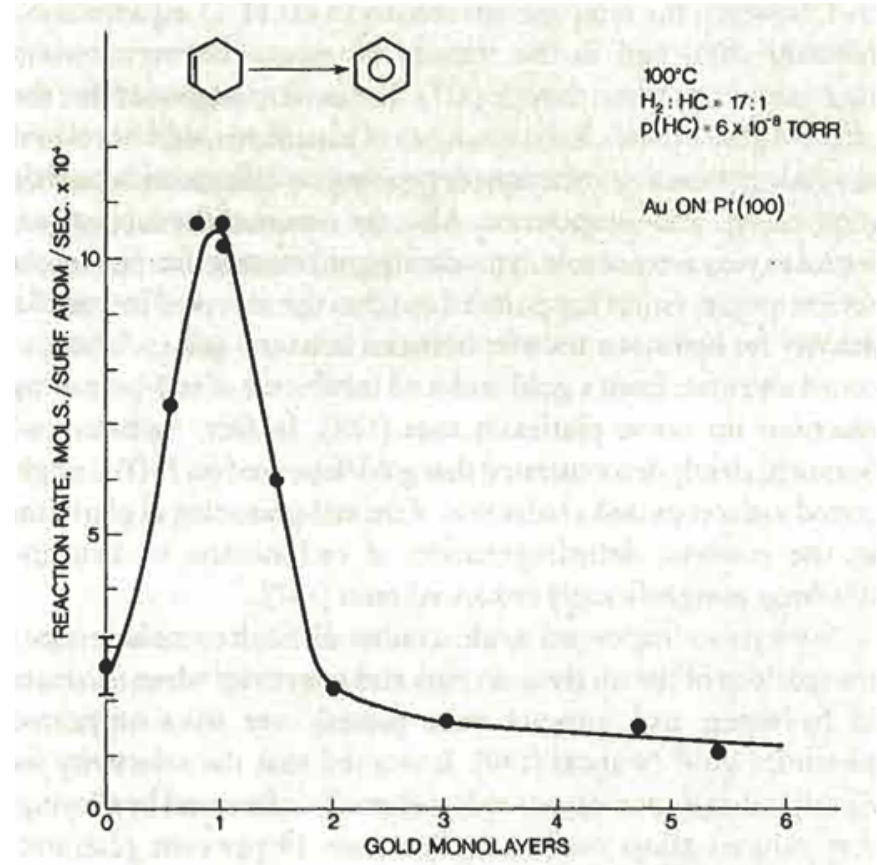

Fig. 5 Rate of cyclohexene dehydrogenation to benzene as a function of gold surface coverage on $\mathrm{Pt}(100)$. After (124)

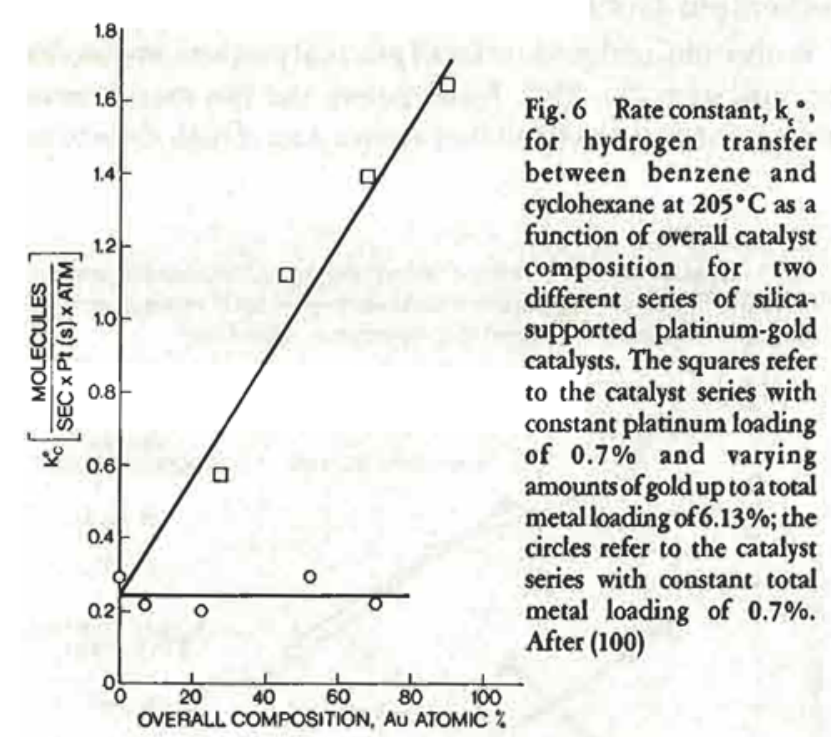

In a study of hydrogen transfer between benzene and cyclohexane, one series of platinum-gold catalysts with a total metal loading of 0.7 per cent behaved like monometallic platinum, irrespective of overall composition, while a similarly prepared series of bimetallic catalysts with higher total metal loading but constant platinum loading of 0.7 per cent showed an increase in activity as a function of gold content (100) (Figure 6). The two catalyst series, 
had, however, the same specific activity in the $\mathrm{H}_{2}-\mathrm{D}_{2}$ equilibration reaction (100) and in the transfer of oxygen between carbon monoxide and carbon dioxide (127). The authors suggested that the effect of gold on the cataly tic activity of platinum could be related to subtle electronic interactions depending on differences in particle morphology and composition. Also, the nature of the support was found to play a major role in rendering gold more active. In a recent review article, Guczi has pointed out that the observed increase in activity for hydrogen transfer between benzene and cyclohexane could also arise from a gold-induced inhibition of self-poisoning reactions on active platinum sites (128). In fact, Sachtler and Somorjai clearly demonstrated that gold deposited on $\mathrm{Pt}(111)$ single crystal surfaces caused a reduction of the self-poisoning of platinum in the catalytic dehydrogenation of cyclohexane to benzene resulting in significantly enhanced rates (141).

Such poisoning events made it rather difficult to make an exact comparison of the catalytic activity and selectivity when mixtures of hydrogen and butanol were passed over silica-supported platinum-gold catalysts (129). It seemed that the selectivity for dibutyl ether formation was only marginally influenced by alloying; very diluted alloys containing less than 14 per cent platinum behaved more like gold.

\section{Ruthenium-Gold}

Ruthenium and gold are for all practical purposes immiscible in the bulk state $(93,130)$. Nevertheless, the two metals seem to undergo interactions when they are in a state of high dispersion on

Fig. 7 Specificactivity for ethane hydrogenolysis and methane formation in the Fischer-Thopsch synthesis on ruthenium-gold catal ysts supported on magnesia or silica as a function of gold content. After (138)

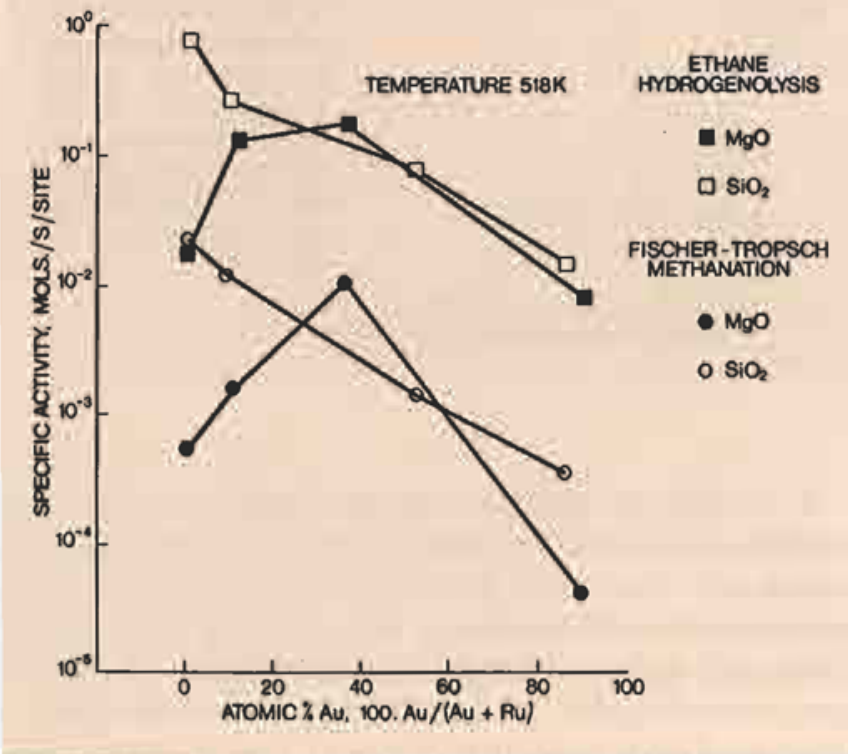

typical catalyst support materials, and an extensive effort has been made to correlate the activity of these bimetallic catalysts with their morphology, structure and composition (131-138). Two series of ruthenium-gold catalysts with varying gold content were prepared, one series supported on silica, the other on magnesia. On magnesia supports, an enrichment of ruthenium on the surface was found $(133,135)$ in contradiction to the general rule that the group $\mathrm{Ib}$ metal segregates at the surface. The magnesia-supported catalysts also showed some rather peculiar behaviour in the structuresensitive hydrogenolysis of ethane (135) and in the carbon monoxide hydrogenation (138).

Figure 7 shows a comparison of the specific activity of nuthenium in both reactions for the silica- and magnesia-supported catalyst series. The magnesia-supported catalysts exhibit a maximum in turnover number at intermediate gold content, while the activity of the corresponding silica-supported series falls with increasing gold content. These activity trends, though they may appear contradictory at first glance, can be explained on the basis of analytical electron microscopy results (138), which demonstrate that the silica-supported catalyst series has a bimodal particle size distribution. There are a few large, monometallic gold particles with a diameter of more than $15 \mathrm{~nm}$, and then many small (less than 4 $\mathrm{nm}$ diameter) particles which contain all the ruthenium plus a trace of gold. The decrease in activity can be correlated with progressive dilution of ruthenium ensembles by gold. The preferentially ruthenium-rich composition of the small bimetallic particles found by analytical electron microscopy is not necessarily out of tune with the gold-ruthenium phase diagram with its miscibility gap. The small trace of gold can easily be accommodated in less than a monolayer of gold atoms that are 'adsorbed' on the surface of small ruthenium particles (139).

In the magnesia-supported ruthenium-gold catalyst series, no such bimodal particle size distribution was observed. Instead, particles ranging in size up to $15 \mathrm{~nm}$ and containing both metals were found, along with monometallic ruthenium and monometallic gold particles.

The major contribution to the metal surface area in the catalysts with low and intermediate gold contents, which exhibited the unusual increase in specific activity, stems from particles in the size range of 5 to $15 \mathrm{~nm}$. Analytical microscopy of these particles gave results which do not conform with what could be expected if the particles were formed by 'adsorption' of up to a monolayer of gold on the ruthenium surface. True alloy formation, on the other hand, does not appear to be very likely since it would require a violation of the bulk immiscibility. Indirect evidence indicates that these particles might be composites of monometallic gold and monometallic ruthenium: in a temperature programmed reduction(TPR) study it was discovered that on magnesia metallic gold can form before ruthenium is reduced to a significant extent, while on silica the two metals get reduced in the same temperature range (137). Furthermore, the increase in activity as a function of 
gold content is not necessarily due to a promotional effect on gold, but can be explained on the basis of support effects: magnesia exerts a negative support effect on monometallic ruthenium, as can be seen by the comparison with the ruthenium/silica catalyst in Figure 7. In the bimetallic catalyst, some of the ruthenium might get deposited on top of gold rather than on activity-suppressing magnesia and thus part of the intrinsic activity of ruthenium is restored. The magnesia-supported catalyst with high gold content, however, shows a decrease in specific activity similar to the one seen in the silica series. Incidentally, this catalyst has a morphology reminiscent of the silica series, with a bimodal particle size distribution and all the ruthenium located within small particles, less than $4 \mathrm{~nm}$ in diameter.

\section{Conclusions}

Bimetallic catalysts can be rather non-uniform and can show massive variations in catalyst morphology and in particle composition, at least in systems with limited bulk miscibility of the metal components. In order to arrive at meaningful interpretations of trends in catalytic activity as a function of overall composition, it is important to identify which kind of particles make the largest contribution to the metal surface area and thus carry the main burden of catalytic action. The nature of the support and the preparative conditions play a decisive role in determining the microstructural characteristics of the active catalyst surface. In many instances, gold seems to act more or less as an inert diluent, and ensemble or cluster effects seem to dominate the catalytic behaviour. These ensemble effects can be utilized to manipulate catalytic selectivity. Presence of gold can under certain conditions also influence the rate of self-poisoning of the active component and can cause changes in surface coverage of adsorbed species, resulting sometimes in apparent increases in specific activity.

\footnotetext{
References

$1 \mathrm{~J}$. Schwank, Gold Bull, 1983, 16, 103-110

2 A. Couper and D.D. Eley, Disc. Faraday Soc, 1950, 8, 172-184

3 D.D. Eley and P. Luetic, Trans. Faraday Soc., 1957, 53, 1483-1487

4 A.G. Daglish and D.D. Eley, in 'Actes 2ième Congr. Intern. de Catalyse', Pari 1960, Vol. 2 (Technip, Paris, 1961), pp. 1615-1624

5 D.D. Elcy and C.F. Knights, Proc. Roy. Soc. Ser. A, 1966, 294,

6 D.D. Eley, J. Res. Inst. Catalysis, Hokkaido Univ., 1968, 16, 101

7 J.A. Nicholson, J.D. Riley, R.C.G. Leckey, J.G. Jenkin and J. Liesegang, J. Electron Specirosc. Related Phenom, 1979, 15, 95-99

8 D.D. Eley and P.B. Moore, Surf. Sci, 1981, 111, 325

9 J.H. Sinfelt, J. Gatal., 1973, 29, 308-315

10 J.B. Darby, Acta Met., 1966, 14, 265

11 F.L. Williams and D. Nason, Surf. Sci, 1974, 45, 377

12 B.J. Wood and H. Wise, Surf. Sci, 1975, 52, 151

13 G. Maire, L. Hilaire, P. Legare, F.G. Gault and A. O'Cinneide,J. Catal., 1976. 44,293

14 A. Jablonski, S.H. Overbury and G.A. Somorjai, Sutf. Sci, 1977, 65, 578

15 D.D. Eley and P.B. Moore, J.C.S. Faraday I, 1980, 76, 1388-1390

16 K.M. Sancier and S.H. Inami, J. Catal, 1968, 11, 135-142

17 Y,L, Lam and M. Boudart, J. Calal., 1977, 55, 530-540

18 I.A. Zubovich and N.N. Migulina, Zh. Vses. Khim. O-va, 1979, 24, 202-203

19 H.R. Gerberich and W.K. Hall, Nature, 1967, 213,1120

20 H.R. Gerberich, N.W. Cant and W.K. HaIl, J. Calal., 1970, 16, 204-219

21 D.M. McClain, C.A. Heller and I.L. Mador, F. Pat. 2,118,774 (1972)

22 J.A. Scheben, J.A. Hinnenkamp and I.L., Mador, Ger: Offen 2529365 (1976)

$23 \mathrm{H}$. Kinza and G. Alscher, Ger,(East) Pat. 106,557(1974)
}

24 K. Sennewald, W. Vogt, H. Erpenbach and H. Glaser, S.Afr. Pat. 6802,009(1968) 25 J. Schroeder, Z. Zabrzeski, J. Jarmakowicz, J. Terlecki and L. Wyrwa, Pol.PL $120,847(1983)$

26 Y.L. Lam, J. Criado and M. Boudart, Nonv. J. Chim., 1977, 1, 461-466

27 M. Boudart and Y.L. Lam, U.S. Pat. 4,136,062 (1979)

28 D.L. Weissman-Wenocur and W.E. Spicer, Surf. Sci. 1983, 133, 499.515

29 E.L. Kugler and M. Boudart, J. Catal., 1979, 59, 201-210

$30 \mathrm{M}$. Nakamura and $\mathrm{H}$. Wise, in 'Proceedings of the Sixth Inter. Congress on Catalysis, London 1976', edited by G.C. Bond, P.B. Wells, F.C. Tompkins, Vol 2, 881-893, The Chemical Society, London, 1977

31 A.A. Alchuzhdan and M.A. Mantikyan, Izvest. Akad. Nauk Armyan S.S.R. Khim. Nanki, 1959, 12, 153-158

32 A.A. Alchuzhdan and E.T. Kristosturyan, Izvest. Akad. Nark Armyan S. S.R. Khim. Nauki, 1959, 12, 305.312

33 A.A. Alchuzhdan M.A. Mantikyn and A.M. Aikazyan, Izvest. Akad. Nawk Armyan S.S.R, Khim. Nauki, 1964, 17, 368-374

34 G. Aguilar, V.M. Gryaznov, L.F. Pavlova and V.D. Yagodovskii, React. Kinet. Catal. Leth, 1977, 7, 181-186

35 B.J. Wood and H. Wise, J. Catal., 1966, 5, 135-145

36 R.S. Yolles, B.J. Wood and H. Wise, J. Catal., 1971, 21, 66.69

37 S.H. Inami and H. Wise, J. Catal., 1972, 26,92-96

38 A. O'Cinneide and J.K.A. Clarke, J. Catal., 1972, 26, 233-241

39 C. Horrex, R.B. Moyes and R.C. Squire, in 'Proceedings of the Fourth International Congress on Catalysis, Moscow, 1968', Paper No. 25

40 L.K. Frevel and L.J. Kressley, U.S. Pat. 2,802,889 (1957); Ger. Offen. 1052979 (1959)

41 C. Visser, J.G.P. Zuidwijk and V. Ponec, J. Calal., 1974, 35, 407-416

42 H.G. Rushford and D.A. Whan, Faraday Trans., 1971, 67, 3377

43 A. O'Cinneide and FG. Gault, J. Catal, 1975, 37, 311-323

44 B.J. Joice, J.J. Rooney, P.B. Wells and G.R. Wilson, Disc. Faraday Soc., 1966, 41, $223-236$

45 J.H. Sinfelt, A.E. Barnett and G.W. Dembinski, U.S. Pat. 3,442,973 (1969)

46 J.H. Sinfelt, A.E. Barnett and J.L. Carter, U.S. Pat.3,769,201 (1973)

47 J.H. Sinfelt and J.L. Carter, Ger. Offen. 2225364 (1972)

48 J.R. Kiturcll, U.S. Pat. 3,576,736

49 G.L. Kaiser, U.S. Pat. 3,974,102; U.S. Pat. 4,000,207

50 R.L. Moss and L. Whalley, Adv. Catal., 1972, 22, 115-189

51 J.K.A. Clarke and E.A. Rafter, Z. Phys. Chem. Neue Folge, 1969, 67, 169-177

52 D.D. Eley and D.M. Macmahon, J. Colloid Interface Sci., 1972, 38, 502-510

53 I.A. Zubovich, Zhur. Fiz. Kbim., 1955, 29, 917-929

54 I.A. Zubovich, Zhur. Fiz. Khim., 1957,31,61-71

$55 \mathrm{~K}$. Sennewald, W. Vogt, H. Erpenbach, H. Glaser, G. Roscher and W. Riemenschneider, Ger. Offen. 1227249 (1968)

56 Fi: Pat. 1,554,729(1969)

57 K. Sennewald, W. Vogt, H. Erpenbach and H. Glaser, S.Afr. Pat. 6802,010(1968)

58 K. Sennewald, W. Vogt, H. Erpenbach and H. Glaser, S. A fr. Pat. 6802,015 (1968)

59 K. Sennewald, W. Vogt, H. Glaser and H. Erpenbach, Ger, Offen. 1301306 (1969)

60 W. Kroenig, G. Roscher, W. Schwerdtel and K. Sennewald, S.Afr. Pat. 6706,730 (1968)

61 W. Kroenig and G. Scharfe, Ger. Offen. $1283226(1968)$

62 C.W. Capp, Fr. Pat. 1,566,124 (1969)

63 Fr. Demande 2,004,036(1969) 10

64 K. Sennewald, W. Vogt, H. Glaser and H. Erpenbach, A. Ohorodnik and H. Joest, Ger, Offen. $1804347(1970)$

65 National Distillers and Chemical Corp., Ger. Offen. $1944933(1970)$

66 T. Saito, M. Takano, S. Moriyama and H. Murayama, Japan. Kokai 73-49,711 (1973)

67 S. Nakamura, T. Tsumura and T. Yasui, Japan. Kokai 73-71,387 (1973)

68 G.M. Severs, Jr., Ger: Offen. 2361098 (1974)

69 O.D. Frampton, Ger: Offen. 2511364 (1975)

70 S. Nakamura, Y. Fujiwara and T. Yasui, Ger. Offen. $2538863(1976)$

71 S. Nakamura, Y. Fujiwara and T. Yasui, Ger: Offen. $2528363(1976$

72 K. Kawai, Y. Fujiwara and M. Nakamura, Japan. Kokai 77-04,490(1977)

73 G. Scharfe, Ger. Offen. $2601154(1977)$

74 T.C. Bissot, U.S. Pat. 4,048,096 (1977)

75 L.A. Sokolova, N.M. Popova, V.K. Eritsyan, B.S. Mukanova, V.K. Boyadzhyan and S.S. Khachatryan, Izv. Akad. Nawk Kaz. S.S.R., Ser. Khim., 1978, 28, 57-60 76 F.D. Miller, Fr, Pat. 1,556,524 (1969)

77 A.G. Knapsack, U.K. Pat. 1107495 (1968)

78 S. Schott, D.W. Lum and I.L. Mador, Ger. Offen. 2420374 (1974)

$79 \mathrm{M}$. Boldt, H.J. A'rpe and L. Hornig, U.S. Pat. 3,651,101

80 M. Martin, G. Scharfe and W. Swodenk, Ger, Offen. 2107913

81 W. Vogt, H. Glaser and K. Sennewald, Ger. Offen. $1945528(1971)$

82 F. Wunder, Ger. Offen. $1957680(1971)$

83 K. Sennewald, H. Erpenbach, W. Vogt and H. Joest, Ger, Offen. 1270543 
84 J.H. Murib, U.S. Pat. 4,107,204 (1978)

85 G. Scharfe, J. Grolig, M. Martin, W. Swodenk and W. Dornfeldt, Ger. Offen. $1959780(1971)$

86 D. Freudenberger, F. Wunder and H. Fernholz, Ger. Offen. 2553761 (1977)

87 D. Freudenberger and F. Wunder, Ger. Offen. 2715667 (1978)

88 J. Petro, T. Mathe, S. Szoke, G. Lugosi and L. Feuer, Fr. Demande 2,232,539 (1975)

89 I. A. Zubovitch, Zbur. Fiz. Kbim, 1955, 29, 1696-1705

90 I.A. Zubovitch, Zhur Fiz Khim 1957, 31, 589-508

91 J.A. Scheben and I.L. Mador, in '5th Conf. Catal. Org. Synth.', 1975, pp. 181-201 edited by P.N. Rylander and H. Greenfield, Academic Press, New York, 1976

92 R.F. Vines, 'The Platinum Metals and their Alloys', The International Nickel Company, Inc., New York, 1941

93 M. Hansen and K. Anderko, 'Constitution of Binary Alloys', 2nd ed., McGraw Hill, New York, 1958

94 J.K.A. Clarke, I. Manninger and T. Baird, J. Catal., 1978, 54, $230 \cdot 242$

95 F.J. Kuijers, R.P. Dessing and W.M.H. Sachtler, J. Catal, 1974, 33, 316-321

96 H.C. DeJongste, F.J. Kuijers and V. Ponec, in 'Preparation of Catalysts', edited by B. Delmon, P.A. Jacobs and G. Poncelet, Elsevier, Amsterdam/New York, 1976 , p. 207

97 S.M. Kulifay, J. Amer. Cbem. Soc, 1961, 82, 4916

98 R.S. Miner,Jr., S. Namba and J. 'Turkevich, Stud. Surf. Sci. Catal, 1981, 7, (PL.A. New Horiz Catal ) 160.172

99 J. Turkevich, R.S. Miner, Jr., I. Okura, S. Namba and N. Zacharina, in 'Perspect. Catal., (Proc. 12th Swed. Symp. Catal.)', 1979 (Pub. 1981), pp. 111-122

100 S. Galvagno and G. Parravano, J. Catal., 1979, 57, 272-286

101 P.R. Norton, R.L. Tapping and J.W. Goodale, J. Vac. Sci. Technol., 1977, 14, 446-451

102 K.M. Sancier and S.H. Inami, J. Catal., 1968, 11, 135

103 J.A. Schwarz, R.S. Polizotti and J.J. Burton, J. Vac. Sci. Technol., 1977, 14, 457

104 D.S. Wang, A.J. Freeman and H. Krakauer, Phys. Rev. B: Condens. Matter, 1984, $29,1665-1673$

105 P. Biloen, R. Bouwman, R.A. VanSanten and H.H. Brongersma, in 'Proceedings 7th International Vacuun Congress, and 3rd International Conference on Solid Surfaces', edited by Dobrozemsky et al. Vienna 1977, Vol, 2, p. 1401

106 J.R. Anderson, K. Foger and R.J. Breakspere, I. Catal., 1979, 57, 458-475

107 J.R. Anderson and R.J. Breakspere, in 'Proceedings 7 th International Vacuum Congress, and 3rd International Conference on Solid Surfaces', edited by Dobrozemsky et al, Vienna 1977, Vol. 1, pp. 823-826

108 R. Bouwman and W.M.H. Sachtler, J. Catal., 1970, 19, 127-140
109 D.W. Budworth, F.E. Hoare and J. Preston, Proc. Roy, Soc, 1960, 257, 250

110 A.S. Darling, P.A. Mintern and J.C. Chaston, J. Inst. Met., 1952, 81, 125

111 G.H. Johansson and I.O. Linde,Ann. Phys., 1930, 5, 762

112 J.J. Stephan, V. Ponec and W.M.H. Sachtler, Surface Sci., 1975, 47, 403

113 K. Foger and J.R. Anderson, Appl. Surf. Sci, 1979, 2, 335-351

114 H.C. Dejongste and V. Ponec, J. Catal., 1980, 64, 228-231

115 J.J. Stephan and V. Ponec, J. Catal., 1976, 42, 1-9

116 R.P. Dessing and V. Ponec, J. Catal., 1976, 44, 494-497

117 JW. A Sachtler, Preprints, A.C.S. Div Petrol Chem. 1983, 28, $491-503$

118 J.R.H. van Schaik, R.P. Dessing and V. Ponec, J. Catal., 1975, 38, 273-282

119 J.K.A. Clarke, A.F. Kane and T. Baird, J. Catal., 1980, 64, 200-212

120 R.P. Dessing and V. Ponec, Reaction Kinet, Catal. Lett., 1976, 5, 251

121 K. Foger and J.R. Anderson, J. Catal., 1980, 61, 140-145

122 R.P. Dessing, V. Ponec and W.M.H. Sachtler, J. Chem. Soc, Chem. Commun. $1972,(15), 880-881$

123 D.I. Hagen and G.A. Somorjai, J. Catal., 1976, 41, 466-481

124 J.W.A. Sachtler, M.A. Van Hove, J.P. Bibérian and G.A. Somorjai, Pbys, Rev Lett, $1980,45,1601-1603$

125 A.A. Alchudzan and M.A. Indzhikyan, Zhur Fiz. Khim 1959, 33, 983-987

126 P. Biloen, F.M. Dautzenberg and W.M.H. Sachtler, J. Catal., 1977, 50, 77-86

127 S. Galvagno and G. Parravano, Ber. Bunsenges. Phys. Chem., 1979, 83, 894-899

128 L. Guczi, J. Molec, Catal., 1984, 25, 13-29

129 A. Van der Burg, J. Doornbos, N.J. Kos, W.J. Ultee and V. Ponec, J. Catal. $1978,54,243-253$

130 A.A. Rudnitskii and O.A. Novikova, Russ. J. Inorg. Chem., 1959, 4, 722

131 J. Schwank, G. Parravano and H.L. Gruber, J. Catal., 1980, 61, 19-28

132 S. Galvagno, J. Schwank and G. Parravano, ]. Catal. 1980, 61, 223-231

133 I.W. Bassi, F. Garbassi, G. Vlaic, A. Marzi, G.R. Tauszik, G. Cocco, S. Galvagno and G. Parravano, J. Catal., 1980, 64, 405-416

134 G.R. Tauszik, F. Garbassi and A. Marzi, Gazz. Chim. Ital., 1980, 110, 443-448

135 S. Galyagno, J. Schwank. G. Parravano, F. Garbassi, A. Marziand G.R. Tauszik, J. Catal., 1981, 69, 283-291

136 G. Leofanti, M. Solari, G.R. Tauszik, F. Garbassi, S. Galvagno and J. Schwank, Appl. Catal. 1982, 3, 131-139

137 G.R. Tauszik, G. Leofanti and S. Galvagno, J. Molec. Catal, 1984, 25, 357-366

138 A.K. Datye and J. Schwank, in 'Proc. 8th Inter. Congress on Catalysis', Berlin (West), Vol. 4, pp 587-598, Verlag Chemie Weinheim, West Germany, 1984 139 A.K. Datye, Ph.D. Thesis, The University of Michigan, 1984

140 J.W.A. Sachtler and G.A. Somorjai, J. Catal., 1983, 81, 77-94

141 J.W.A. Sachtler and G.A. Somorjai, J. Catal., 1984, 89, 35-43

\section{Enhanced Bonding of Gold Films by Ion-Assisted Deposition}

One of the basic criteria to be satisfied in thin-film technology is strong adherence of the film to the substrate. Many applications of thin gold films on different substrates are to be found in this technology, and the achievement of good reproducible adhesion between gold and the substrate, in particular glass, still presents a problem on which much work is still being done. One method which has frequently been used to improve the adhesion of films is that of oxygen glow-discharge cleaning of the substrates before the deposition of gold. However the role of oxygen in the process has not been satisfactorily explained, and variable results are often obtained.

Recent work on the development of the technique of ion-assisted film deposition by P.J. Martin, W.G. Sainty, R.P. Netterfield and their co-workers at the Division of Applied Physics, CSIRO, Australia (J. Appl. Phys., 1984, 55, 235 and Appl. Opt., 1983, 22, 178) has enabled thin film properties, particularly refractive index and density, to be modified substantially. In addition, Martin, Sainty and Netterfield have reported (Appl. Opt., 1984, 23, (16), 2668-2669) on their experiments in which thin films of gold on polished glass substrates were deposited by ion-assisted electron beam evaporation, and the adhesion of the films examined.

In this work the films ( $\sim 100 \mathrm{~nm}$ thickness) were deposited (a) without ion assistance, (b) under argon-ion bombardment, and (c) using oxygen-ion bombardment. Gold film adhesion was measured by scratch testing using a diamond stylus with a radius of either 65 or 250 micrometres with fil $\mathrm{m}$ failure being defined as partial or total removal from the $15 \mathrm{~mm}$ scratch track.

The results of this work clearly showed that oxygen-ion assisted gold deposition yielded films with adhesion levels markedly above those formed by normal electron beam evaporation - one to two orders of magnitude improvement are quoted in this work. One undesirable feature of oxygen-ion assisted gold film deposition is the characteristic brown colour of the film leading to some reduction in the film reflectance. The authors have overcome this problem by switching off the oxygen-ion beam once a continuous film has been formed, and continuing gold evaporation to final film thickness. By this means high adhesion without loss in reflectance is achieved.

Argon-ion assisted gold deposition shows little or no improvement in film adhesion and the authors suggest that the mechanism by which adhesion is increased with the use of oxygenion assistance involves the formation of a stable compound at the point of film formation which bonds the gold film to the substrate. The brown colouration of the gold film may also, of course, suggest some formation of gold oxide.

The success of this work is a welcome addition to the literature describing the ongoing effort to improye the adhesion of gold films for use in thin film technology.
C.I. 